\title{
Cohort effects in older drivers' accident type distribution: are older drivers as old as they used to be?
}

Reprint from Transportation Research Part F 2 (1999), pp. 131-138

Liisa Hakamies-Blomqvist, VTI, and Swedish School of Social Science, University of Helsinki, Finland Per Henriksson, VTI

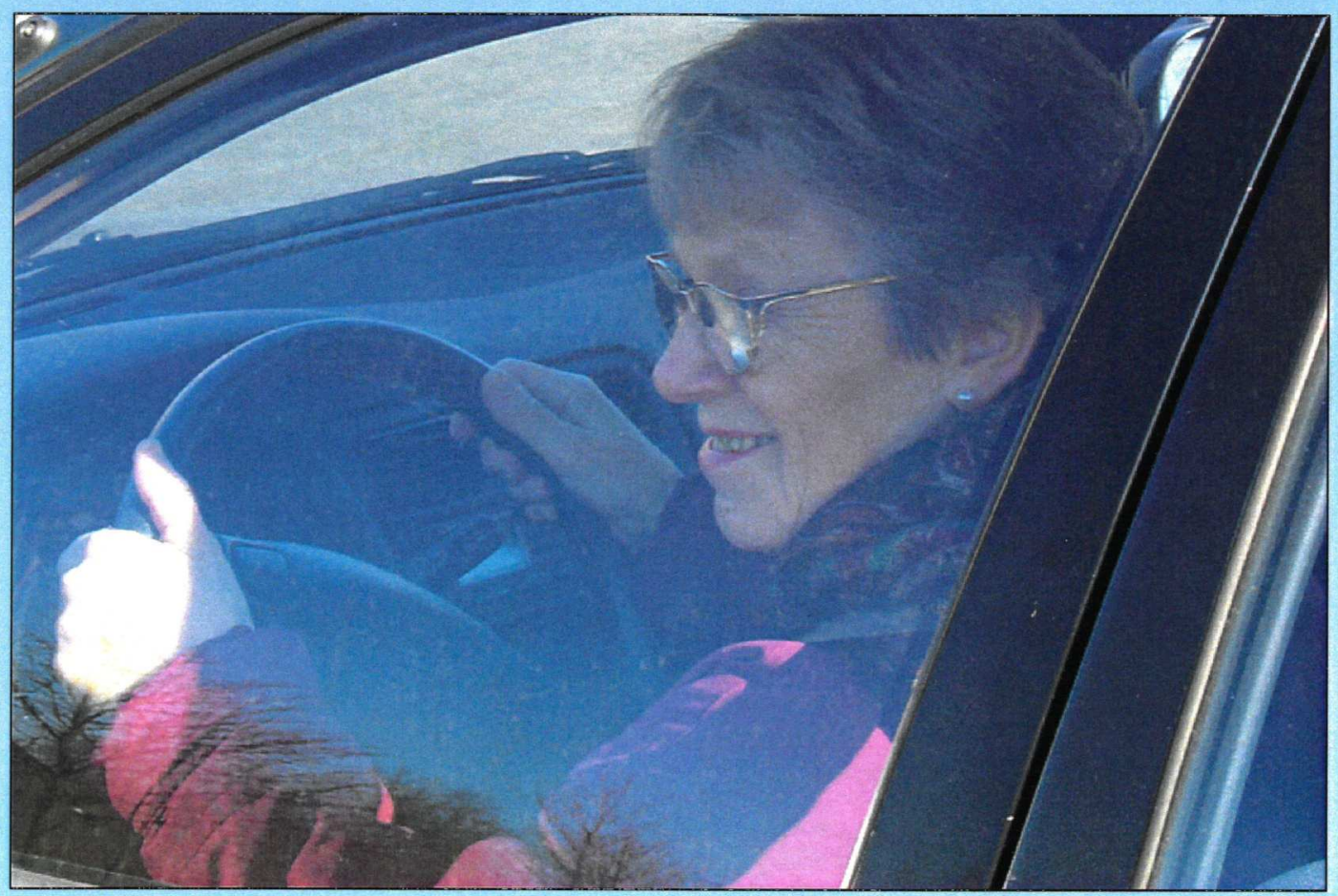




\section{VTI särtryck $338 \cdot 2000$}

\section{Cohort effects in older drivers' accident type distribution: are older drivers as old as they used to be?}

Reprint from Transportation Research Part F 2 (1999), pp. $131-138$

Liisa Hakamies-Blomqvist, VTI, and Swedish School of Social Science, University of Helsinki, Finland Per Henriksson, VTI 


\title{
Cohort effects in older drivers' accident type distribution: are older drivers as old as they used to be?
}

\author{
Liisa Hakamies-Blomqvist $^{\mathrm{a}, \mathrm{b}, *}$, Per Henriksson ${ }^{\mathrm{b}}$ \\ a Swedish School of Social Science, University of Helsinki, P.O. Box 16 (Topeliusgatan 16), 00014 Helsinki, Finland \\ ${ }^{\mathrm{b}}$ Swedish Road and Transport Research Institute (VTI), Linköping, Sweden
}

Received 4 January 1999; received in revised form 10 April 1999; accepted 12 April 1999

\begin{abstract}
Accident type distributions were compared in successive cohorts of older drivers, with focus on intersection accidents. It was thought that if the increasing share of intersection accidents is a truly age-related phenomenon, as opposed to cohort-related or time-related, it would remain fairly constant over time in different cohorts. The data consisted of Finnish traffic insurance data on private car accidents of drivers aged $60 \mathrm{yr}$ or more who were legally responsible for causing the accident, and covered the years 1987-1995 $(N=56,481)$. Some changes in accident type distributions were found across cohorts. Among male drivers aged 60-79 yr, the portion of intersection accidents decreased in successive cohorts, so that the younger cohorts showed the age-typical accident picture at a somewhat later age than the older cohorts. In contrast, for male drivers aged $80 \mathrm{yr}$ or more, there was an increase in the share of intersection accidents in more recent cohorts. Among female drivers, a decrease in intersection accidents only reached statistical significance for drivers aged 60-69 yr, and for the oldest age group (75+ yr) no change was observed. For both male and female drivers, the tendency to incur accidents at intersections increased with age in all cohorts. The occurrence of intersection accidents thus is both an age-related and a cohort-related phenomenon: agerelated in the sense that it will emerge eventually, but with cohort-related variance in timing. (C) 2000 Published by Elsevier Science Ltd. All rights reserved.
\end{abstract}

Keywords: Older driver; Accident; Cohort

\footnotetext{
* Corresponding author. Department of Psychology, Swedish School of Social Science, University of Helsinki, P.O. Box 16 (Topeliusgatan 16), FIN-00014 Helsinki, Finland. Tel.: +358 94050 0295; fax: +358 940500245.

E-mail address: liisa.hakamies-blomqvist@helsinki.fi (L. Hakamies-Blomqvist)
}

1369-8478/00/\$ - see front matter (C) 2000 Published by Elsevier Science Ltd. All rights reserved.

PII: S 1369-8478(99)00009-1 


\section{Introduction}

The proportion of older drivers in the driver population increases in the industrialized world as a consequence of the aging of populations, and of increasing licensing rates in successive cohorts of older citizens. Research efforts have been dedicated to describe and understand the accident epidemiology of older drivers (for a review, see Eberhard, 1996; Hakamies-Blomqvist, 1996). The generalizability of the accumulated findings can be questioned, however. Private car use is a relatively recent phenomenon. During the active driving career of the present older drivers, the task environment has undergone profound changes. The traffic environment and culture, including the design of cars, roads, and rule systems, and the rhythm of road traffic, are all very different to what they were in the beginning of the present older drivers' learning history. Hence, their specific experience pattern may produce outcomes that will not be repeated among future cohorts who most probably will have a more homogeneous learning history. In addition, while the present older drivers are a select group and have mostly learned to drive as adults, in future cohorts of older citizens the majority will be license holders and they will have started driving at an earlier age. Hence, when findings about older drivers' accident epidemiology are presented, it is difficult to say which aspects, if any, are truly age-related, and which ones merely cohort-specific phenomena.

A few studies have addressed the question of accident rates among different cohorts of older drivers. Evans concluded that the severity of the "older driver problem" was exaggerated because it was largely based on studies confounding age and cohort effects (Evans, 1993). Similarly, Stamatiadis (1995) found that cohorts of older drivers born later had smaller risks than cohorts born earlier. Comparing older drivers' representation in the licensed driver population to agerelated crash trends, Stutts showed that crash rates did not increase in keeping with the increasing proportion of older drivers; this was especially true for females and nonwhite drivers (Stutts \& Martell, 1992). All these studies used data from the US. While these combined findings strongly suggest that the accident rates of older drivers have been decreasing in successive cohorts, little or nothing is known about possible cohort effects in the kind of accidents older drivers have. Yet, there are certain fairly constant traits in older drivers' accident epidemiology, as described in cross-sectional research, which in principle make it possible to analyze not only accident rates but also accident characteristics.

Arguably the most consistent finding regarding older drivers' accident types is that older drivers tend to have with age increasing portions of their accidents in intersections and in other complex situations (Cooper, 1990; Hakamies-Blomqvist, 1993; Hakamies-Blomqvist, 1994a). Correspondingly, the proportion of other types of accidents decreases. Thus, an overrepresentation of accidents in intersection can reasonably be considered an older-driver-like characteristic. In the present study we compared the accident type distributions of successive cohorts of older drivers, with focus on intersection accidents. It was thought that if the increasing share of intersection accidents is a truly age-related phenomenon, as opposed to cohort-related or time-related (for a methodological discussion, see Nesselroade \& Labouvie, 1985), it would remain fairly constant over time in different cohorts. We use the expression "age-related" in a broad sense covering any relevant factors covarying with chronological age, i.e., both the effects of normal aging and the effects of, e.g., illnesses with age-related increase in prevalence. 


\section{Materials and methods}

The basic data consist of all traffic accidents occurring in Finland in the years 1973-1995, and leading to claims on insurance policies accepted by the insurance companies, excluding cases where the age of the driver was under 18 or unknown $(N=1,641,411)$. According to earlier studies, these insurance data cover approximately $78 \%$ of all traffic accidents and about $86 \%$ of all injury accidents. Underrepresented are mainly single-vehicle accidents that do not lead to personal injury. The data are recorded per insured vehicle of the paying, i.e., legally responsible party. Thus, all data about drivers presented below are data about drivers at fault, exclusively. In the .5\% of cases with shared legal responsibility, the same accident appears more than once in the database.

For the purposes of the present study, only data on private car drivers aged $60 \mathrm{yr}$ or more were included, excluding cases with missing gender information. Since the aim of the study was to follow up in time the accident type distributions of different older driver cohorts, it was imperative that the data be coded in a consistent manner during the period covered by the analysis. However, a more detailed coding system had been introduced in 1987, and codes in the data before and after 1987 could not be reliably matched. Hence, the analysis was limited to the years 1987-1995. The final number of accident-involved drivers included in the study thus was 56,481, divided into age and gender groups as shown in Table 1.

The present analysis focused on changes between cohorts in the proportion of intersection accidents. To determine whether the changes were statistically significant, the slope coefficients of regression lines fitted to the observed data were compared to zero (i.e., no change); alpha was set at .05. All changes reported in Section 3 were statistically significant, if nothing else is specified in the text.

Table 1

Number of accident-involved drivers according to year of accident, age, and gender

\begin{tabular}{|c|c|c|c|c|c|c|c|c|c|c|}
\hline \multirow{2}{*}{$\begin{array}{l}\text { Year of } \\
\text { accident }\end{array}$} & \multicolumn{4}{|c|}{ Male-age group } & \multirow[t]{2}{*}{ Total M } & \multicolumn{3}{|c|}{ Female-age group } & \multirow[t]{2}{*}{ Total F } & \multirow[t]{2}{*}{$\mathrm{M}+\mathrm{F}$} \\
\hline & $60-69$ & $70-74$ & $75-79$ & $80+$ & & $60-69$ & $70-74$ & $75+$ & & \\
\hline 87 & 3230 & 877 & 568 & 317 & 4992 & 496 & 82 & 72 & 650 & 5642 \\
\hline 88 & 3289 & 942 & 557 & 415 & 5203 & 592 & 101 & 110 & 803 & 6006 \\
\hline 89 & 3287 & 827 & 639 & 355 & 5108 & 594 & 126 & 106 & 826 & 5934 \\
\hline 90 & 3379 & 954 & 677 & 298 & 5308 & 655 & 132 & 71 & 858 & 6166 \\
\hline 91 & 3306 & 984 & 686 & 337 & 5313 & 729 & 154 & 99 & 982 & 6295 \\
\hline 92 & 3350 & 1061 & 697 & 370 & 5478 & 682 & 139 & 116 & 937 & 6415 \\
\hline 93 & 3099 & 1041 & 676 & 421 & 5237 & 694 & 204 & 146 & 1044 & 6281 \\
\hline 94 & 3334 & 1128 & 694 & 501 & 5657 & 846 & 171 & 133 & 1150 & 6807 \\
\hline 95 & 3176 & 1207 & 766 & 568 & 5717 & 835 & 239 & 144 & 1218 & 6935 \\
\hline Total & 29,450 & 9021 & 5960 & 3582 & 48,013 & 6123 & 1348 & 997 & 8468 & 56,481 \\
\hline
\end{tabular}




\section{Results}

In the following figures, in case of collisions between vehicles, the accidents were classified according to the relative driving directions of the colliding vehicles. The three categories of collisions thus were "same driving directions", "opposing driving directions", and "crossing driving directions". The other categories of accidents used in the present analysis were "hitting a pedestrian", "single-vehicle accident", and "other".

\subsection{Male drivers}

As shown in Fig. 1, those accident-involved male drivers who were between 60 and 69 yr of age in 1987 had a larger share of their accidents in intersections than those being in the same age range in 1995. From 1987 to 1995 the proportion of intersection accidents went down from 35\% to $30 \%$.

A similar trend was observed for male driver cohorts aged 70-74 yr (Fig. 2) and 75-79 yr (Fig. 3). While the share of intersections accidents of all accidents increased with age, it decreased

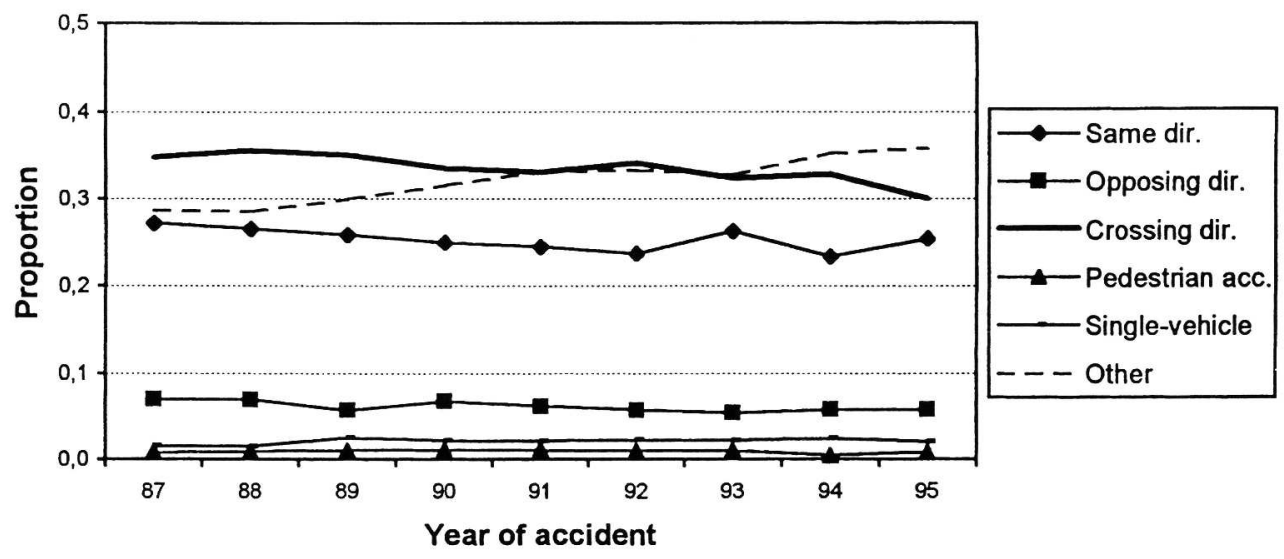

Fig. 1. Accident type distribution in successive cohorts of male drivers aged 60-69 yr.

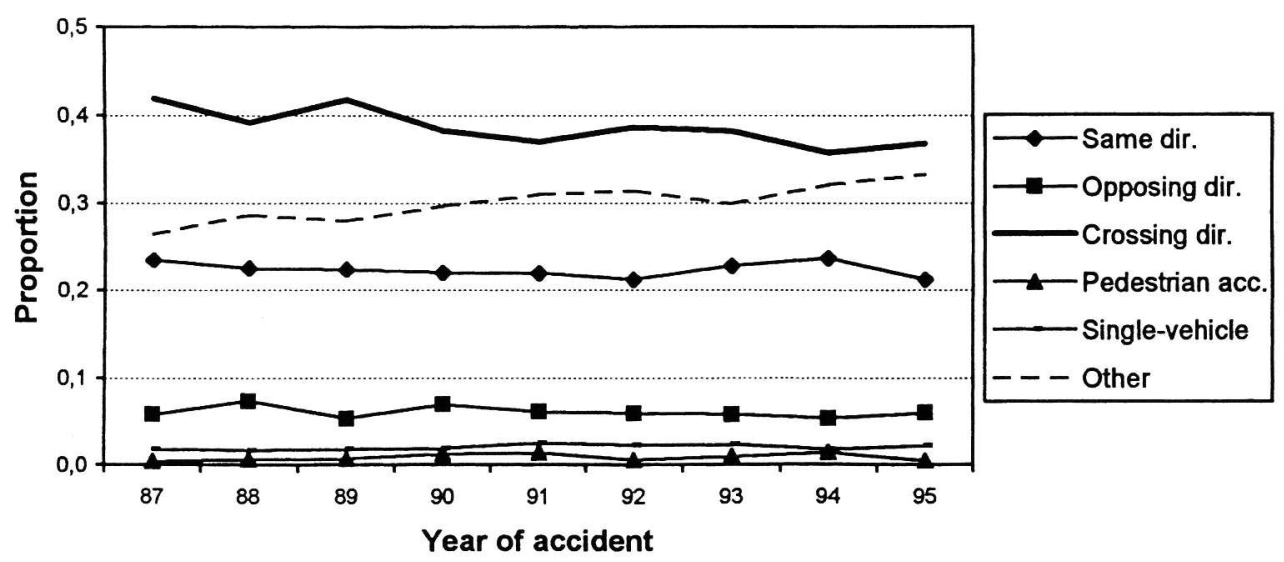

Fig. 2. Accident type distribution in successive cohorts of male drivers aged 70-74 yr. 


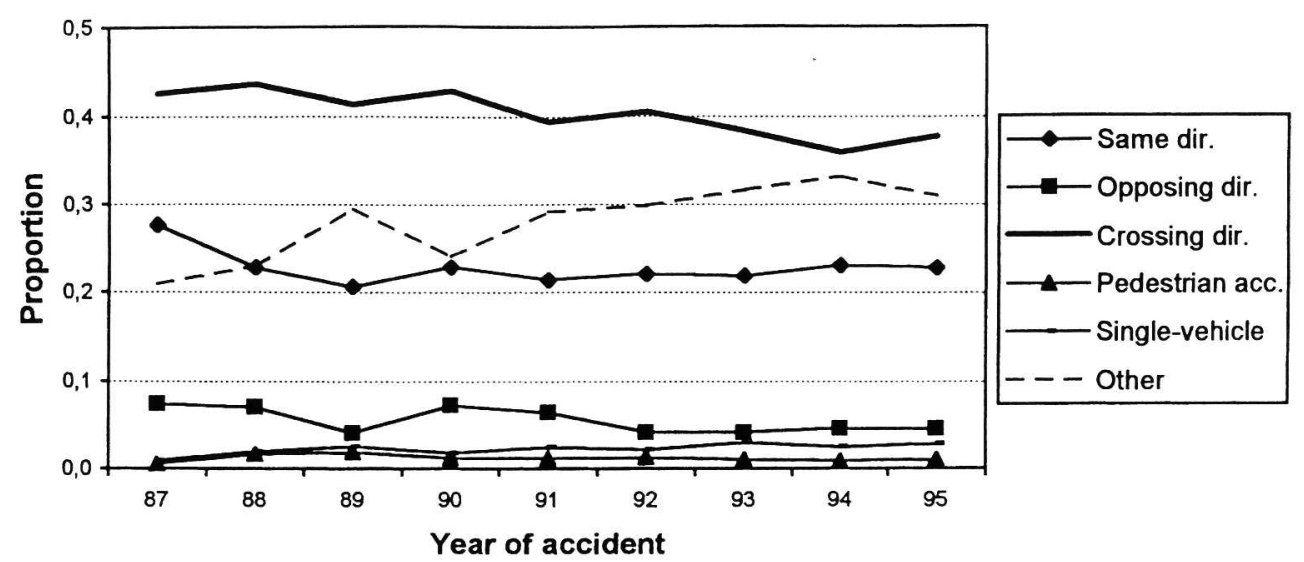

Fig. 3. Accident type distribution in successive cohorts of male drivers aged 75-79 yr.

in successive cohorts, so that the more recent cohorts had a less "older-driver-like" accident type distribution.

For the oldest male drivers, the cohort comparison showed a different trend (Fig. 4). In the age group $80+$, the more recent the cohort, the higher was the proportion of intersection accidents among their accidents.

\subsection{Female drivers}

For female drivers aged 60-69 yr, the proportion of intersection accidents decreased in successive cohorts (Fig. 5). In the age group 70-74 yr, a similar trend did not reach statistical significance (Fig. 6).

In the oldest age group of female drivers $(75+)$, the absolute numbers of accidents were so small that possible trends could be blurred by random noise; however, the distribution of accident types appeared stable across the different cohorts (Fig. 7).

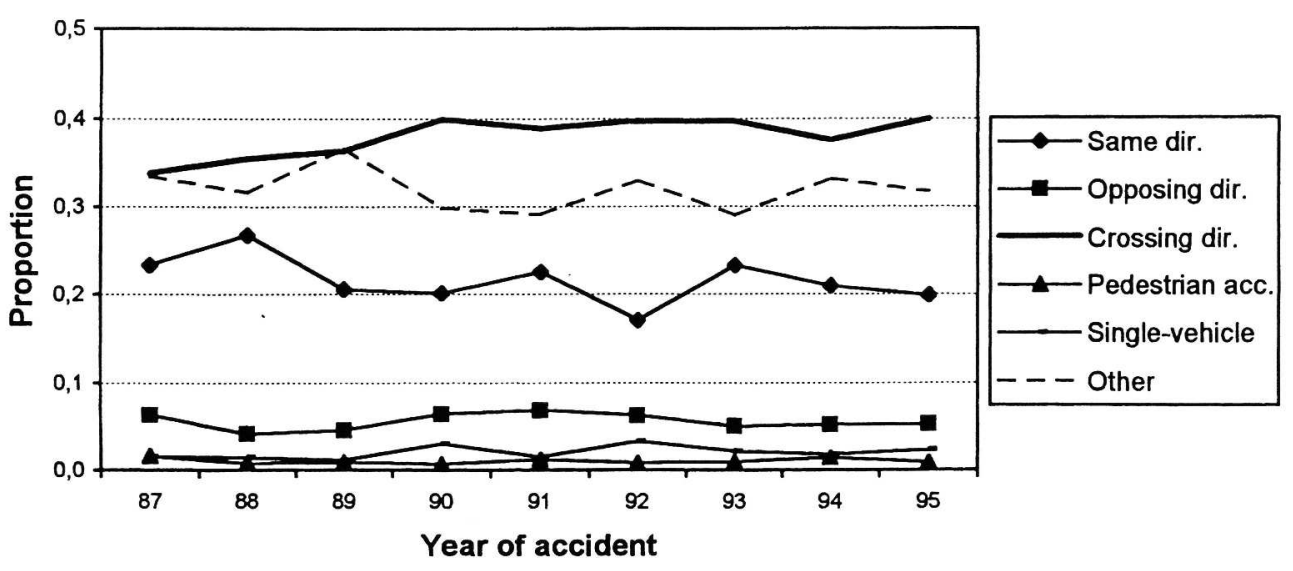

Fig. 4. Accident type distribution in successive cohorts of male drivers aged $80 \mathrm{yr}$ or more. 


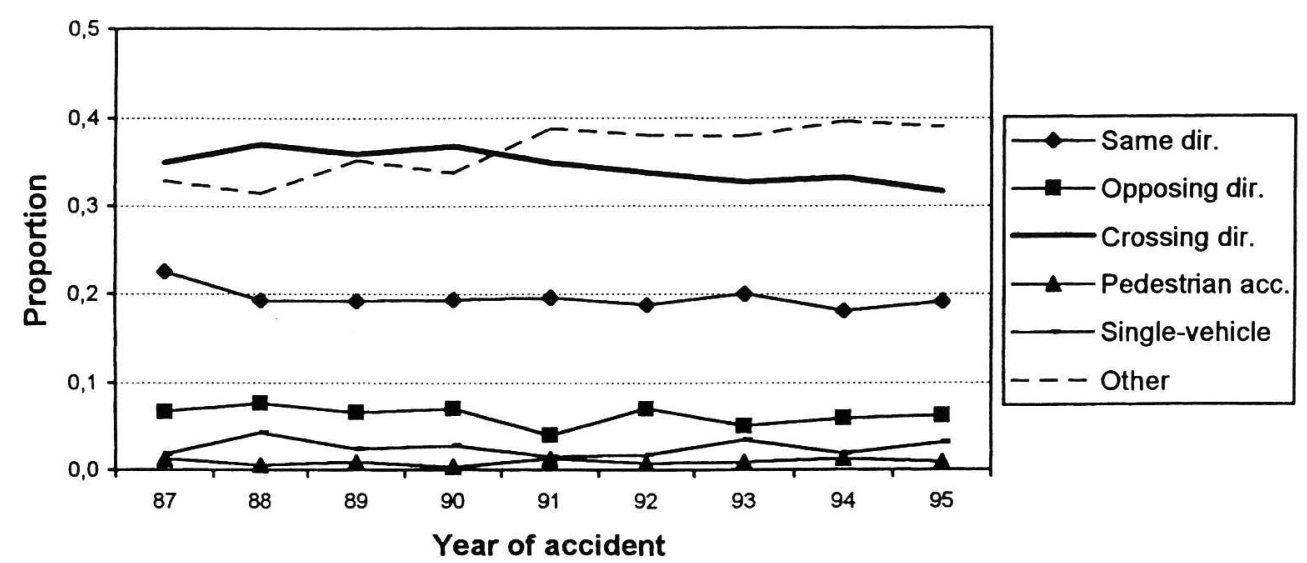

Fig. 5. Accident type distribution in successive cohorts of female drivers aged 60-69 yr.

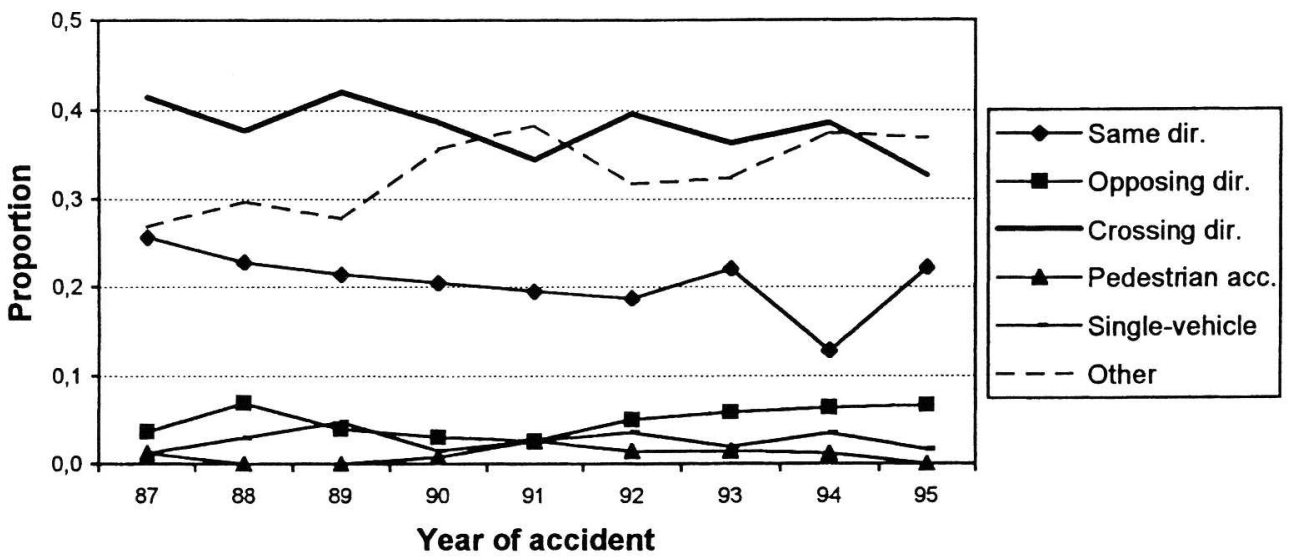

Fig. 6. Accident type distribution in successive cohorts of male drivers aged $70-74 \mathrm{yr}$.

\section{Discussion}

In the present study, certain changes in accident type distributions were found across cohorts. Among male drivers aged 60-79, the proportion of intersection accidents decreased in successive cohorts, so that the younger cohorts showed the older-driver-like accident picture at a somewhat later age than the older cohorts. On the other hand, for male drivers aged $80 \mathrm{yr}$ or more, there was an increase of the share of intersection accidents in the more recent cohorts. Among female drivers, a decrease in intersection accidents only reached statistical significance for drivers aged 60-69 yr. For the oldest age group, 75+ yr, no change was observed.

The decrease in intersection accidents among younger cohorts as compared to older ones seems to indicate that the more recent cohorts indeed do "age later" as drivers; in other words, they acquire the typical accident type distribution at a higher age than their predecessors. This finding is in harmony with earlier findings showing that more recent cohorts have smaller accident risk than more distant ones (Evans, 1993; Stamatiadis, 1995; Stutts \& Martell, 1992). Whatever the reasons hereof, it shows that the dominance of intersection accidents is both an age-related and a cohort-related phenomenon: age-related in the sense that it will emerge eventually, but with 


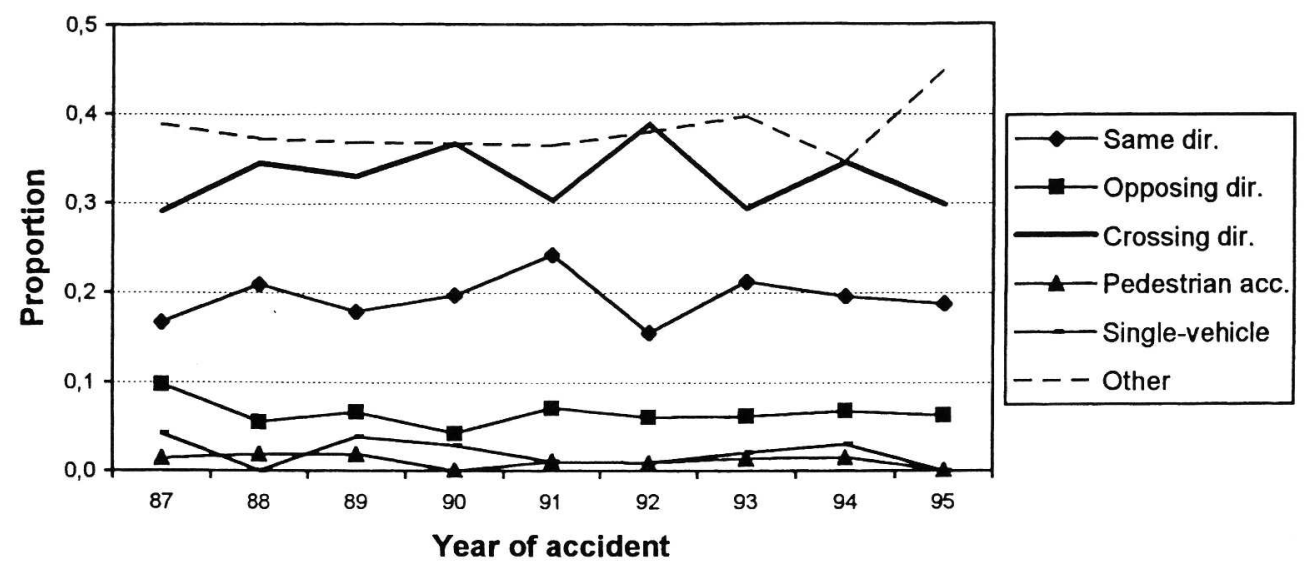

Fig. 7. Accident type distribution in successive cohorts of female drivers aged 75 yr or more.

cohort-related variance in timing. As to the third parameter, that of time, it seems plausible there have been changes in the traffic environment between 1987 and 1994 that may have improved the safety of intersections. However, since the direction of the observed changes was not the same in all cohorts, improvements in the environment cannot be the sole explanation of the present findings.

The finding that the oldest drivers of the more recent cohorts have increasing portions of intersection accidents does not have any straightforward interpretation. It does not seem plausible that the drivers aged $80+$ in the more recent cohorts would be less fit or less experienced than those in the earlier cohorts. However, since in every successive cohort, license holding and active driving becomes more common (Barr, 1991) it is safe to assume that the earlier cohorts of drivers aged $80+$ were more select subpopulations of their cohorts than the more recent ones. When driving up to a high age becomes common, variance in health- and performance-related variables within the group of the oldest drivers increases (Hakamies-Blomqvist, 1998). The current and future oldest drivers will be an increasingly representative sample of their age group in the general population, probably including a larger proportion of drivers with risk-increasing functional deficits. It is also possible that the driving habits of the oldest drivers have changed. However, with no additional information accessible, these attempts to explain the finding remain somewhat speculative.

While the present findings showed some differences between the different cohorts, the tendency to incur accidents in intersections increased with age in all cohorts. This does not mean, however, that it would be due to age per se; rather, it covaries with age as do a number of other things, including prevalence of different risk-increasing health conditions and functional deficits. Intersection driving is a complex, forced-paced task during which several subtasks have to be performed within a limited amount of time defined by a combination of physical layout and speed limits of the intersection, which places a heavy momentary load on the driver (HakamiesBlomqvist, 1996). In such a task, many age- or illness-related functional deficits may affect the level of performance negatively and increase the probability of mistakes. Because of the nature of the task, the usual compensatory mechanism (Cooper, Tallman, Tuokko \& Beattle, 1993; Hakamies-Blomqvist, 1994b) of winning more time by choosing to operate on lower speeds is not applicable. 
To conclude, future cohorts of older drivers will grow old as drivers at a somewhat later age than the present ones. The typical accident patterns of increasing rates of serious accidents and increasing shares of accidents in intersections will, however, eventually emerge. For the oldest drivers, the safety trend may even be worsening when larger percentages of license holders in the oldest age groups continue driving. Hence, both research efforts and safety measures focusing on the needs and problems of the aging drivers will be needed.

\section{Acknowledgements}

Financial support from the Swedish Communication Research Board is gratefully acknowledged. We also wish to thank the Finnish Traffic Safety Committee of the Insurance Companies for their generous assistance with the data base.

\section{References}

Barr, R. A. (1991). Recent changes in driving among older adults. Human Factors, 33, 597-600.

Cooper, P. J. (1990). Differences in accidents characteristics among elderly drivers and between elderly and middle-age drivers. Accident Analysis and Prevention, 22, 499-508.

Cooper, P. J., Tallman, K., Tuokko, H., \& Beattle, B. L. (1993). Safety-related driving performance changes in older drivers. Journal of Traffic Medicine, 21, 21-27.

Eberhard, J. W. (1996). Safe mobility for senior citizens. IATSS Research, 20, 29-37.

Evans, L. (1993). How safe were today's older drivers when they were younger? Paper presented at the Transportation Research Board, 72nd Annual Meeting, 10-14 January, Washington DC.

Hakamies-Blomqvist, L. (1993). Fatal accidents of older drivers. Accident Analysis and Prevention, 25, $19-27$.

Hakamies-Blomqvist, L. (1994a). Aging and fatal accidents in male and female drivers. Journal of Gerontology, Social Sciences, 49, S286-S290.

Hakamies-Blomqvist, L. (1994b). Compensation in older drivers as reflected in their fatal accidents. Accident Analysis and Prevention, 26, 107-112.

Hakamies-Blomqvist, L. (1996). Research on older drivers: A review. IATSS Research, 20, 91-101.

Hakamies-Blomqvist, L. (1998). Older drivers' accident risk: Conceptual and methodological issues. Accident Analysis and Prevention, 30, 293-297.

Nesselroade, J. R., \& Labouvie, E. W. (1985). Experimental design in research on aging. In J. E. Birren, \& K. W. Schaie (Eds.), Handbook of the Psychology of Aging. New York: Van Nostrand Reinhold Company.

Stamatiadis, N. (1995). Trends in highway safety: Effects of an aging population on accident propensity. Accident Analysis and Prevention, 27, 443-459.

Stutts, J. C., \& Martell, C. (1992). Older driver population and crash involvement trends, 1974-1988. Accident Analysis and Prevention, 24, 317-327. 
VI FORSKAR FÖR ETT LIV I RÖRELSE

Statens väg- och transportforskningsinstitut (VTI) har kompetens och laboratorier för kvalificerade forskningsuppdrag inom transporter och samhällsekonomi, trafiksäkerhet, fordon, miljö samt för byggande, drift och underhăll av vägar och järnvägar.

The Swedish National Road and Transport Research Institute (VTI) has laboratories and know-how for advanced research commissions in transport and welfare economics, road safety, vehicles and the environment. It also has research capabilities for the construction, operation and maintenance of roads and railways.

\section{Adress}

Postal address

SE-581 95 Linköping, Sweden
Telefon

Telephone

Nat 013-20 4000

Int +4613204000
Fax

E-post

E-mail

Nat 013-14 1436

Int +4613141436 